\title{
ANALISA STRATEGI BISNIS PT XYZ DALAM INDUSTRI RETAIL FASHION DI INDONESIA
}

\author{
Maria Novianti \\ Program Studi Magister Manajemen Universitas Tarumanagara \\ novianti.maria@gmail.com
}

Masuk : 07-06-2020, revisi : 26-06-2020 diterima untuk diterbitkan : 29-06-2020

\begin{abstract}
The purpose of this study is to identify internal and external factors that affect the company, which is engaged in the fashion retail industry, in the fashion retail industry, and to find out the right and effective business strategies to improve the company's sales performance in the face of intense competition in fashion retail industry in Indonesia. Data collection techniques performed by the author are primary data (interviews and observations) and secondary data (sales data, inventory data, case studies and literature). The stages of analysis conducted by the author are divided into three stages, namely the input stage, followed by the matching stage, and the final stage is the decision analysis stage. The results of this study are about three strategies that can be used by companies, Product Development with a score of 6.46, Market Development with a score of 5.93 and Related Diversification holding the highest score of 6.64 .
\end{abstract}

Abstrak: Tujuan penelitian ini untuk mengidentifikasi faktor-faktor internal dan eksternal apa saja yang mempengaruhi perusahaan, yang bergerak di bidang retail fashion, dalam industri retail fashion, serta untuk mengetahui strategi bisnis yang tepat dan efektif untuk meningkatkan kinerja penjualan perusahaan dalam menghadapi persaingan yang ketat dalam industri retail fashion di Indonesia. Teknik pengumpulan data yang dilakukan oleh penulis adalah data primer (wawancara dan observasi) dan data sekunder (data penjualan, data stok barang, studi kasus dan kepustakaan). Tahapan analisa yang dilakukan oleh penulis terbagi menjadi tiga yaitu tahap masukan (Input Stage), dilanjutkan dengan tahap pencocokan (Matching Stage), dan tahap terakhir adalah tahap analisa keputusan (Decision Stage). Hasil dari penelitian ini adalah ada tiga strategi yang dapat digunakan oleh perusahaan yaitu Produk (Product Development) dengan skor 6.46, Pengembangan Pasar (Market Development) dengan skor 5.93 dan Diversifikasi Terkait (Related Diversification) memegang skor yang paling tinggi yaitu 6.64.

Keywords: Fashion Retail, Business Strategy, Related Diversification

\section{PENDAHULUAN}

Perkembangan teknologi telah menciptakan suatu industri baru yaitu industri 4.0, yang mendorong tumbuhnya perdagangan elektronik dan perubahan pola belanja langsung. Hal ini membuat pasar di Indonesia semakin kompetitif dan perubahan pola bisnis yang serba cepat. Persaingan usaha yang ketat dan menuntut kecepatan mengharuskan perusahaan untuk fokus pada kemampuannya dalam bersaing dan bertahan di dalam dunia bisnis. Untuk itu diperlukan penerapan strategi bisnis yang tepat dalam mencapai tujuan perusahaan dalam memenangkan persaingan usaha.

Mencermati dinamika usaha ini, perusahaan dituntut untuk mengembangkan dan meningkatkan pengetahuan manajemen dan sumber daya manusia, serta menciptakan strategi bersaing yang tepat dan berorientasi ke depan. Hal ini dapat membuat keunggulan bersaing yang dimiliki perusahaan semakin baik dan siap menghadapi kompetisi usaha.

Industri yang akan penulis teliti adalah industri retail fashion di Indonesia. Berkembangnya bisnis retail fashion ditandai dengan banyaknya mall-mall yang bermunculan, 
hal ini menandakan bahwa sektor retail adalah industri yang perkembangannya sangat cepat. Seiring dengan perkembangan yang pesat, perubahanpun semakin cepat mengikuti perkembangan teknologi. Munculnya perdagangan elektronik yang ditandai dengan tumbuhnya pasar digital di Indonesia, yang memberikan kemudahan dan kecepatan dalam berbelanja, membuat pasar perdagangan langsung menjadi kurang diminati. Hal ini menyebabkan persaingan usaha di industri retail fashion semakin ketat.

Pesatnya pembangunan pusat perbelanjaan, tren belanja konsumen yang cenderung wait and see seiring dengan berjalannya tahun politik, dan pelambatan ekonomi dunia yang turut menekan daya beli masyarakat, menuntut perusahaan untuk memiliki strategi yang tepat dalam menjalankan bisnisnya. Namun banyak juga beberapa peluang yang dapat dimanfaatkan seperti tren masyarakat yang peka akan produk original, sektor pariwisata yang semakin baik ditandai dengan adanya penerbangan langsung dari china ke manado dan bali sepanjang tahun 20182019, dan lainnya.

Penulis meneliti perusahaan yang bergerak dibidang retail fashion, yang telah berdiri kurang lebih 20 tahun lamanya. Melihat data penjualan tiga tahun terakhir yang mulai ada penurunan dan tantangan industri baru 4.0, membuat penulis tertarik untuk melakukan penelitian pada perusahaan ini. Karena dengan usia perusahaan yang cukup lama, banyak sekali tantangan, peluang dan permasalahan baik internal dan eksternal yang harus diantisipasi oleh perusahaan, agar siap menghadapi persaingan dalam industry retail fashion yang selalu dinamika perubahannya cepat dan selalu up to date.

\section{Tujuan Penelitian}

1. Untuk mengidentifikasi faktor-faktor internal dan eksternal apa saja yang mempengaruhi PT XYZ dalam industri retail fashion.

2. Untuk mengetahui strategi bisnis yang tepat dan efektif agar kinerja penjualan PT XYZ dapat meningkat dalam menghadapi persaingan yang ketat dalam industri retail fashion di Indonesia.

\section{TINJAUAN PUSTAKA}

\section{Definisi Manajemen Strategi}

Manajemen Strategi dapat didefinisikan sebagai suatu proses untuk menentukan arah dan tujuan organisasi dalam jangka panjang beserta pemilihan metode untuk mencapainya melalui pengembangan formulasi strategi dan implementasi yang terencana secara sistematis (Susanto, 2014:2).

Menurut Pearce \& Robinson (2015:3) strategic management is defined as the set of decisions and actions that result in the formulation and implementation of plans designed to achieve a company's objectives.

Menurut David \& David (2017:33) strategic management is the art and science of formulating, implementing, and evaluating cross-functional decisions that enable an organization to achieve its objectives. Sedangkan menurut Pearce II \& Robinson (2015:3) strategic management is defined as the set of decisions and actions that result in the formulation and implementation of plans designed to achieve a company's objectives.

Dari pengertian diatas dapat disimpulkan bahwa manajemen strategi memfokuskan pada integrasi semua lini manajemen baik pemasaran, keuangan, produksi, riset dan pengembangan serta sistem informasi untuk mencapai tujuan perusahaan.

\section{Model Manajemen Strategi}

Kristianti (2017) menyatakan tahapan dalam manajemen strategis terdiri dari tiga tahapan penting yaitu (pp. 3-4):

1. Formulasi strategi.

2. Implementasi strategi. Dalam tahap ini sering dikenal sebagai "action stage" dari manajemen strategi. 
3. Evaluasi strategi. Terdapat tiga aktivitas mendasar dalam mengevaluasi strategi, yaitu (1) melakukan review faktor-faktor internal dan eksternal yang menjadi dasar strategi saat ini, (2) mengukur kinerja atau performa, dan (3) Mengambil tindakan koreksi.

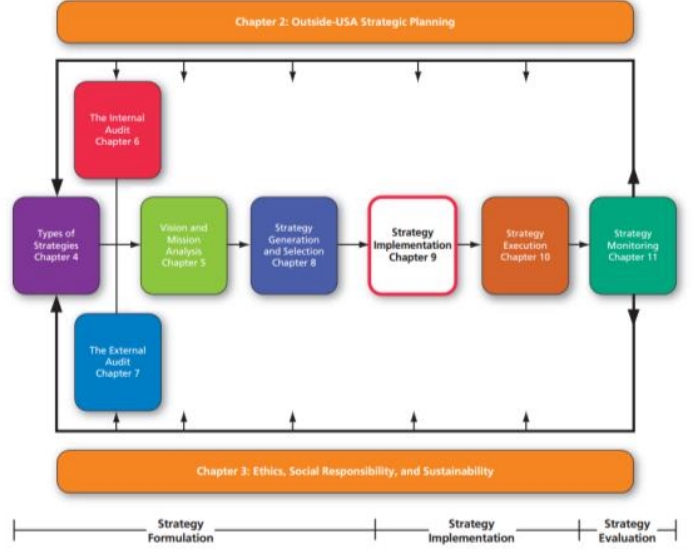

\section{Gambar 1}

Model Manajemen Strategi David \& David (2017:42)

Analisis Persaingan Industri: Porter's Five -Forces Model

Untuk dapat menghasilkan suatu strategi bagi perusahaan, perlu dilakukan analisa kekuatan dalam menghadapi persaingan dalam industri. Menurut Porter, persaingan dalam industry dapat meliputi lima kekuatan antara lain (Kristianti, 2017:17):

1. Persaingan antar perusahaan di dalam industry. Strategi bersaing yang efektif meliputi tindakan-tindakan ofensif ataupun defensive guna menciptakan posisi yang aman pada kondisi persaingan.

2. Potensi masuknya pesaing baru. Ketika banyak perusahaan memasuki industry dengan mudah, maka persaingan antara perusahaan akan semakin meningkat.

3. Potensi adanya produk subtitusi. Produk-produk subtitusi (pengganti) adalah produk yang dapat menjalankan fungsi yang sama seperti produk dalam industry.

4. Kekuatan tawar menawar dari pemasok. Pemasok dapat menggunakan kekuatan tawar menawar para peserta industry dengan mengancam akan menaikkan harga atau menurunkan mutu produk atau jasa yang dibeli.

5. Kekuatan tawar menawar dari pembeli. Pembeli dapat menuntut perusahaan untuk memaksa harga turun, tawar menawar untuk mutu yang lebih tinggi dan pelayanan yang lebih baik.

\section{Kerangka Kerja Analisa Formulasi Strategi \\ Input Stage}

Tahapan Masukan (Input Stage) dilakukan untuk mendapatkan informasi mendasar dalam penyusunan dan perumusan strategi. Dalam tahap ini terdapat 3 matrix yang dapat digunakan yaitu IFE Matrix untuk menganalisa kekuatan dan kelemahan perusahaan, EFE Matrix untuk menganalisa faktor eksternal yang dapat menjadi peluang dan ancaman baik bagi perusahaan maupun indsutri, dan yang ketiga yaitu CPM Matrix untuk menganalisa profil competitor perusahaan.

\section{Matching Stage}

Pada tahap ini seluruh analisa internal dan eksternal perusahaan diselaraskan untuk mendapatkan strategi yang tepat bagi perusahaan. Adapun alat bantu yang digunakan adalah SWOT Matrix, SPACE Matrix, dan Grand Strategy Matrix.

\section{Decision Stage}

Quantitative Strategic Planning Matrix (QSPM), adalah tahap 3 dari kerangka kerja analitis formulasi strategi, secara objektif menunjukkan strategi alternatif mana yang terbaik. QSPM menggunakan input dari analisis Tahap 1 dan mencocokkan hasil dari analisis Tahap 2 untuk memutuskan secara objektif di antara strategi alternatif. QSPM adalah alat yang memungkinkan ahli strategi untuk mengevaluasi strategi alternatif secara objektif, berdasarkan 
pada faktor-faktor kunci sukses eksternal dan internal yang telah diidentifikasi sebelumnya. Pada tahap ini adalah pemilihan atas keputusan strategi yang akan digunakan untuk mencapai tujuan perusahaan.

\section{METODOLOGI PENELITIAN Objek Penelitian}

PT. XYZ berdiri sejak tahun 2000 dengan fokus usaha perdagangan retail fashion. Perusahaan ini mendistribusikan salah satu brand internasional berupa pakaian jadi. Sebelumnya perusahaan bergerak dibidang konveksi pakaian jadi dengan nama perusahaan yang berbeda. Pengalaman dibidang tekstil khususnya produksi pakaian yang sudah bertahuntahun dilakukan oleh perusahaan telah membawa PT. XYZ, mendapatkan kepercayaan untuk memasarkan produk dengan brand internasional asal amerika serikat, di Indonesia pada tahun 2000. Segmentasi konsumen adalah para wisatawan luar negri, dikarenakan brand tersebut sudah terkenal di luar dan dalam negri.

Perusahaan memiliki store yang tersebar di seluruh Indonesia berjumlah 90 store dan 78 store konsinyasi berupa rekanan dan departement store seperti Metro Dept. Store, Centro Dept. Store, Star Dept. Store, Citrus Dept. Store, Central Dept. Store, dan lainnya. Sehingga total saluran distribusi barang per tahun 2019 berjumlah 168 store.

Rantai nilai (fashion value chain) dari PT XYZ adalah sebagai berikut:

1. Dalam memproduksi barang, merujuk pada standarisasi principal yaitu pemilik brand yang berada di Amerika. Barang yang diproduksi terbatas dan disesuaikan dengan kebutuhan store yang ada.

2. Desain dan pengembangan produk tersentralisasi, namun ada beberapa produk yang disesuaikan dengan kultur atau musim (season) yang ada di Indonesia.

3. Produk diproduksi secara in-house dengan standarisasi yang ditentukan oleh principal.

\section{Jenis dan Periode Penelitian}

Menurut tujuannya, metodologi penelitian yang digunakan adalah penelitian terapan. Menurut Barlian (2016:18), penelitian terapan (applied research) — ditujukan untuk penerapan, atau pengujian, teori-teori dan pemanfaatannya dalam memecahkan suatu masalah. Sementara metodologi yang digunakan dalam penelitian ini adalah deskriptif - kualitatif. Penelitian deskriptif (descriptive research) yang dilakukan untuk menjawab pertanyaan yang berkaitan dengan status objek penelitian pada saat penelitian diadakan, atau dengan kata lain, menginformasikan keadaan sebagaimana adanya (Barlian, 2016:19). Penelitian kualitatif, dimana prosedur penelitiannya menghasilkan data deskriptif berupa kata-kata atau lisan dari orang-orang dan perilaku yang dapat diamati (Siyoto dan Sodik, 2015:17). Penulis melakukan penelitian pada perusahaan PT. XYZ, merupakan perusahaan yang bergerak di bidang retail fashion. Dengan periode pengambilan data dan analisa perusahaan tahun 2017 sampai dengan tahun 2019.

\section{Sumber dan Pengumpulan Data}

Sumber data yang digunakan adalah data primer (wawancara dan observasi) dan data sekunder (data penjualan, data stok barang, studi kasus dan kepustakaan). Sementara teknik pengumpulan data diperoleh dengan teknik wawancara dan observasi objek penelitian.

Data primer di perusahaan digunakan untuk mengevaluasi faktor-faktor internal dan eksternal baik di dalam perusahaan maupun di industri retail fashion. Data diperoleh dari dokumen perusahaan baik berupa hard copy maupun soft file serta melakukan diskusi dan wawancara dengan narasumber. Data sekunder diambil dari jurnal, buku, dan internet yang membahas mengenai manajemen strategi. Sumber data sekunder dalam penelitian ini diambil dengan melakukan pengumpulan data dari publikasi jurnal dan berita, baik yang dimuat di media internet, televisi dan media massa. 


\section{Metode analisis}

Penulis menggunakan tahapan metode analisa dibawah ini, untuk menghasilkan strategi yang sesuai dengan kebutuhan dan kondisi perusahaan yang diteliti:

1. Tahap Masukan (Input Stage): IFE Matriks, EFE Matriks dan CPM Matriks

2. Tahap Pencocokan (Matching Stage): TOWS analisis, Matriks SPACE dan Grand Strategy Matriks

3. Tahap Keputusan (Decision Stage): QSPM Matriks

\section{HASIL DAN KESIMPULAN}

Analisa atas faktor-faktor eksternal dan internal yang mempengaruhi perusahaan adalah:

\begin{tabular}{|l|}
\hline KEKUATAN (STRENGTH) \\
\hline 1. International brand \\
2. Biaya produksi yang murah \\
3. 168 saluran distribusi di seluruh Indonesia \\
4. Persediaan barang dagangan yang cukup \\
5. Promosi dan konsep store yang selalu \\
update \\
6. Sudah memiliki online store dan masuk di \\
beberapa market place
\end{tabular}

\section{PELUANG (OPPORTUNITIES)}

1. Peningkatan jumlah wisatawan ke Indonesia sepanjang 2017 - 2019

2. Harga jual lebih rendah diantara negara lain

3. Pertumbuhan ekonomi yang stabil, sehingga daya beli masyarakat meningkat

4. Customer loyal yang masih besar

5. Gaya hidup berbusana yang berubah, dimana bangga menggunakan produk original

\section{KELEMAHAN (WEAKNESSES)}

1. Asumsi customer asing karena harga lebih murah dari negara lain

2. SDM yang kurang mumpuni

3. Desain produk yang terbatas

4. Analisa penjualan tidak maksimal

5. Biaya operasional store offline cukup tinggi

6. Website online store sering down (tidak stabil)

\section{ANCAMAN (THREATS)}

1. Dampak perang dagang antara Amerika dan China serta kenaikan suku bunga oleh Bank Sentral Amerika.

2. Masyarakat terbiasa berbelanja secara on-line yang lebih praktis dan hemat waktu. Yang berdampak pada store offline.

3. Persaingan usaha yang tidak sehat dengan produk sejenis yaitu brand lokal serupa dan brand palsu lainnya yang di jual di mangga dua dan tanah abang.

4. Faktor alam dan politik, seperti bencana alam yang terjadi di sepanjang tahun 2018 sampai 2019 dan tahun politik 2019.

5. Perubahan teknologi yang cepat dan masif, menyebabkan perubahan gaya hidup masyarakat yang ingin mendapatkan pelayanan yang cepat dan eksklusif.

Dari hasil matriks QSPM dengan hasil tiap-tiap strategi yaitu Pengembangan Produk (Product Development) dengan skor 6.46, Pengembangan Pasar (Market Development) dengan skor 5.93 dan Diversifikasi Terkait (Related Diversification) memegang skor yang paling tinggi yaitu 6.64. Sehingga strategi yang perlu difokuskan oleh PT. XYZ adalah Diversifikasi Terkait. Diversifikasi produk dapat dilakukan dengan mulai memproduksi pakaian bayi, mengembangkan produk yang sudah ada yaitu pakaian olahraga golf. Memproduksi produk second line, untuk menghadapi tantangan dari pesaing yang memalsukan produk brand internasional. Alih-alih menempuh jalur hukum, lebih baik perusahaan memproduksi produk dengan bahan yang dibawah standar yang ada sekarang, namun tetap nyaman dan dengan harga terjangkau. Sehingga konsumen yang terbiasa membeli barang palsu atau competitor dengan harga yang murah, dapat beralih ke produk second line yang diciptakan perusahaan.

Fokus pengembangan pasar di sektor online, harus sangat serius diperhatikan oleh perusahaan. Budaya masyarakat saat ini yang bergantung akan gadget, adalah perubahan yang tidak bisa dihindari lagi. Keberadaan store offline perlahan akan tergantikan oleh store online. Perusahaan harus mengambil langkah cepat dalam mengembangkan store online-nya, karena tipikal konsumen online sangat berbeda dengan konsumen offline. Pelayanan yang tidak optimal seperti website sering down, tampilan yang tidak menarik, pelayanan customer service yang lambat, pengiriman yang lama dan kendala lainnya, akan berpengaruh terhadap brand image perusahaan. Dan jejak digital akan terekam lama, serta sangat cepat berita negative 
diterima oleh semua orang. Untuk itu diperlukan penanganan khusus dengan menjaga kestabilan koneksi, proforma dan tampilan website. Serta terus melakukan kerjasama dengan market place yang ada di Indonesia dan mulai memasuki market place yang mendunia seperti Alibaba, amazon dan lainnya.

\section{DAFTAR PUSTAKA}

Arrigo, E. (2010). Innovation and market-driven management in fast fashion companies. SYMPHONYA Emerging Issues in Management, 2.

Barlian, E. (2016). Metodologi Penelitian Kualitatif dan Kuantitatif. Padang: Sukabina Press.

David, F. R., \& David, F. R. (2017) Strategic Management: A Competitive Advantage Approach, Concepts and Cases $\left(16^{\text {th }}\right.$ ed.), London: Pearson Education.

Kim, B. (2013). Competitive priorities and supply chain strategy in the fashion industry. Qualitative Market Research: An International Journal, 16(2), 214-242.

Kristianti, R. A. (2017). Manajemen Strategik. Tangerang: Pustaka Mandiri.

Pearce, J. A., \& Robinson, R. B. (2015). Strategic Management: Planning for Domestic \& Global Competition (14 ${ }^{\text {th }}$ ed.). New York: McGraw-Hill Education.

Rangkuti, F. (2013). SWOT Balanced Scorecard: Teknik Menyusun Strategi Korporat yang Efektif plus Cara Mengelola Kinerja dan Risiko. Jakarta: PT Gramedia Pustaka Utama.

Saxena, A. \& Srivastava, S. K. (2017). Online to offline platform: a case study of Firstcry.com. International Journal of Economic Perspectives, 11(3), 424-430.

Siyoto, S., \& Sodik, A. (2015). Dasar Metodologi Penelitian. Yogyakarta: Literasi Media Publishing.

Susanto, A. B. (2014). Manajemen Strategik Komprehensif. Jakarta: Penerbit Erlangga.

Thompson, J. \& McLarney, C. (2017). What effects will the strategy changes undertaken by next PLC have on themselves and their competition in the UK clothing retail market? Journal of Commerce \& Management Thought, 8(2), 234-264. 